\title{
FUNGOS ASSOCIADOS À MUSCA DOMESTICA CAPTURADAS ATRAVÉS DE ARMADILHAS COM ISCA QUÍMICA E BUSCA DIRETA
}

\author{
E.G. Fernandes ${ }^{1}$, M.A.Z. Borges ${ }^{2}$, H.M. Valério ${ }^{2}$
}

${ }^{1}$ Universidade Federal de Viçosa, Departamento de Microbiologia Agrícola, Av. PH Rolfs s/no, CEP 36570000, Viçosa, MG, Brasil. E-mail: eliogomesfernandes@hotmail.com

\section{RESUMO}

\begin{abstract}
Este trabalho avaliou o isolamento de fungos em Musca domestica através da busca direta e por meio de iscas químicas e também a influência desta isca química para o crescimento de fungos encontrados nessas moscas. Foram realizadas coletas usando armadilhas com iscas químicas, compostas do inseticida Imidacloprid e outra por busca direta. Verificou-se que em $71,73 \%$ das moscas coletadas por busca direta apresentaram crescimento fúngico, enquanto as moscas capturadas usando iscas químicas apresentaram apenas $28,26 \%$ de crescimento fúngico. No teste realizado adicionando a isca química em meio de cultura BDA, não foi observado crescimento fúngico. Para estudos de fungos residentes em $M$. domestica, o uso do inseticida Imidacloprid como isca química não é recomendado, pois este produto pode inibir determinados microrganismos, inclusive possíveis biocontroladores de $M$. domestica.
\end{abstract}

PALAVRAS-CHAVE: Moscas, imidacloprid, aviário.

\section{ABSTRACT}

FUNGI ASSOCIATED TO MUSCA DOMESTICA CAPTURED WITH TRAPS CONTAINING CHEMICAL BAIT AND BY DIRECT SEARCH. This study evaluated the isolation of fungi from Musca domestica captured through direct search and chemical baits and also the influence of chemical bait for the growth of fungi found on these flies. Collection using traps with chemical bait, composed of the insecticide Imidacloprid, and a direct search were carried out. It was verified that $71.73 \%$ of the flies collected from the direct search presented fungi growth, whereas only $28.26 \%$ of the flies captured using chemical bait showed fungi growth. In the test carried out with the addition of chemical bait to the BDA media culture, fungal growth was not observed. For studies of fungi resident on $M$. domestica, the use of the insecticide Imidacloprid with chemical bait is not recommended, as this product can inhibit some microorganisms, including potential biocontrols for M. domestica.

KEY WORDS: Musca domestica, imidacloprid, aviary.

A produção avícola de caráter industrial obriga a criação de animais em grandes densidades, principalmente em granjas de postura. A consequência destas práticas é o acúmulo de grandes quantidades de esterco, que é substrato ideal para a criação de dípteros muscóides, principalmente $\mathrm{Musca}$ domestica L. (Díptera: Muscidae) (AxTelL, 1999).

BicHo et al. (2004) constataram, em coleta feita em um aviário, que $61,47 \%$ dos artrópodes existentes no local correspondiam a dípteros.

O principal causador de problemas em aviários é o díptero sinantrópico $M$. domestica que é uma espécie de grande importância médico-veterinária, pois atua como vetor mecânico e/ou biológico de diversos agentes patogênicos, incluindo parasitos do homem e de animais (AxTELL; ARENDS, 1990).
Entre os patógenos veiculados por $M$. domestica destacam-se bactérias como Enterobacter spp., Escherichia coli, Salmonella spp., Shigella spp., Klebsiella pneumoniae, Proteus spp., Citrobacter spp. (RомÁm et al., 2004; UgBogu et al., 2006; BANjo et al., 2005), Vibrio cholera e Staphylococcus aureus (BANJo et al., 2005); protozoários como Entamoeba histolytica e Giardia intestinalis (SALES et al., 2002); vírus como poliovírus e vírus causadores de hepatites (UgBogu et al., 2006) e fungos como Candida spp., Aspergillus fumigatus e Criptococcus spp. (Quiceno et al., 2010).

Uma das formas de monitorar a presença de patógenos ou micro-organismos biocontroladores veiculados por essa mosca é pela captura seguida do isolamento e identificação de micro-organismos (Nunes, 2002; Quiceno et al., 2010). Porém, nem

${ }^{2}$ Universidade Estadual de Montes Claros, Centro de Ciências Biológicas e da Saúde, Montes Claros, Brasil. 
sempre é possível capturar esses insetos devido à baixa densidade populacional, ao contrário do que ocorre em criatórios de animais, onde a densidade populacional émuito grande, então sefaz necessária a utilização de iscas químicas letais.

Sendo assim, este trabalho avaliou o crescimento de fungos residentes em $M$. domestica capturada através de busca direta e armadilhas contendo iscas químicas letais e, em seguida, caracterizou o crescimento dos fungos isolados em meio de cultivo na presença da isca química.

As coletas foram realizadas em 2 galpões de uma granja aviária na região de Montes Claros, MG. Em cada galpão foram colocadas quatroarmadilhas feitas de garrafas tipo PET de 2 L pintadas de amarelo, contendo isca atrativa composta do feromônio tricoseno e do inseticida Imidacloprid. Estas armadilhas permaneceram no aviário durante uma semana. A outra coleta foi realizada por busca direta com auxílio de uma rede entomológica.

Após as coletas, os insetos foram levados ao laboratório de Zoologia da UniversidadeEstadual de Montes Claros (UNIMONTES) onde foram separados e identificados, selecionando-se 200 indivíduos de M. domestica de cada galpão, sendo 100 das coletas por busca direta e 100 da coleta usando armadilhas, totalizando 400 moscas.

No laboratório de Biotecnologia da UNIMONTES, essas moscas passaram por uma antissepsia externa com álcool $70 \%$ por 30 segundos, seguida de imersão em hipoclorito de sódio a $2 \%$ por 1 minuto e subsequente lavagem em água destilada estéril. Após a antissepsia, as moscas foram acondicionadas em câmara úmida, sendo 25 indivíduos por placa de Petri, incubadas em estufa com temperatura $28 \pm 2^{\circ} \mathrm{C}$ e fotofase de 12 horas durante 27 dias.

Fungos crescidos no tegumento do inseto foram isolados em meio de cultivo BDA e, após crescimento micelial, foram repicados, em triplicatas, para meio de cultura BDA acrescentado da isca química contendo o inseticida Imidacloprid, de acordo com as recomendações do fabricante ( $100 \mathrm{~g}$ da isca diluídas em 100 mL de água).

As identificações dos fungos isolados foram feitas através da técnica de microcultivo, de acordo com as características morfológicas sugeridas pelas chaves taxonômicas proposta por Alves (1998) e BARNETT; HUNTER (1998).

Os resultados foram analisados utilizando-se o teste de análise de variâncias fator único (ANOVA), com um nível de significância ( $\alpha$ ) de 0,05 , através do programa estatístico R (R DEVELOPMENT..., 2008).

Em relação ao crescimento dos fungos encontrados nas moscas, houve diferença significativa ( $p=0.04891)$ entre os tipos de captura, sendo que $71,73 \%$ das moscas capturadas por busca direta apresentaram crescimento fúngico, enquanto apenas $28,26 \%$ das moscas capturas por armadilhas contendo iscas químicas apresentaram emergência de fungos (Fig. 1).

Entre os fungos isolados de M. domestica, foram identificadosos gêneros Paecilomycesspp., Scopulariopsis spp.,Memnoniella spp. eAspergillus spp. Na tentativa de cultivo desses fungos em meio BDA, não foi observado crescimento fúngico no tratamento contendo o inseticida, enquanto no tratamento controle foi constatado crescimento normal.

Moino JúnIOR; Alves (1998) demonstraram. em estudo in vitro, que o inseticida Imidacloprid é compatível com algumas espécies fúngicas como Metarhizium anisopliae e Beauveria bassiana e esse mesmo resultado foi obtido por LoureIRO et al. (2002). Entretanto, não foram localizados trabalhos onde a compatibilidade entre as espécies fúngicas isoladas com o inseticida Imidacloprid tenha sido avaliada. Contudo, outros estudos demonstram que vários inseticidas prejudicam o crescimento micelial, a conidiogênese e a esporulação de fungos quando estes são inoculados na presença de outros inseticidas (LOUREIRO et al., 2002).

É bem provável, também, que a alta concentração de soluto no meio de crescimento, após o acréscimo da isca química, tenha tornado o meio decrescimento osmoticamente desfavorável para o crescimento fúngico, inibindo o desenvolvimento desses fungos isolados pós-captura.

A coleta de moscas para averiguação de fungos veiculados é muito importante para prevenção e/ou identificação de possíveis surtos de doenças causados por esses micro-organismos, além de proporcionar um controle de qualidade pelo monitoramento de eventuais patógenos que possam ser introduzidos por essas moscas no aviário. Outro ponto importante no que diz respeito à coleta e no isolamento de fungos é no sentido de que possam ser isolados potenciais agentes de controle dessas moscas, porém nem semprea densidade populacional desses insetos permite realizar capturas de forma direta, sendo então necessário o uso de iscas. Apesar do uso de iscas atrativas ser mais prático no campo pode, eventualmente, interferir no crescimento fúngico. O desenvolvimento de novas técnicas de coleta ou testes com outros inseticidas que não restrinjam ou inibam o crescimento de fungos associados aos insetos em questão, poderia tornar viável o uso de iscas químicas para coleta de insetos e destes, então, isolar e identificar quais fungos podem ser veiculados pelos insetos dentro de uma unidade de criação de animais.

Conclui-se que a coleta de $M$. domestica para isolar fungos usando iscas químicas não é indicada, sendo que a coleta por busca direta não interfere no isolamento dos fungos. 


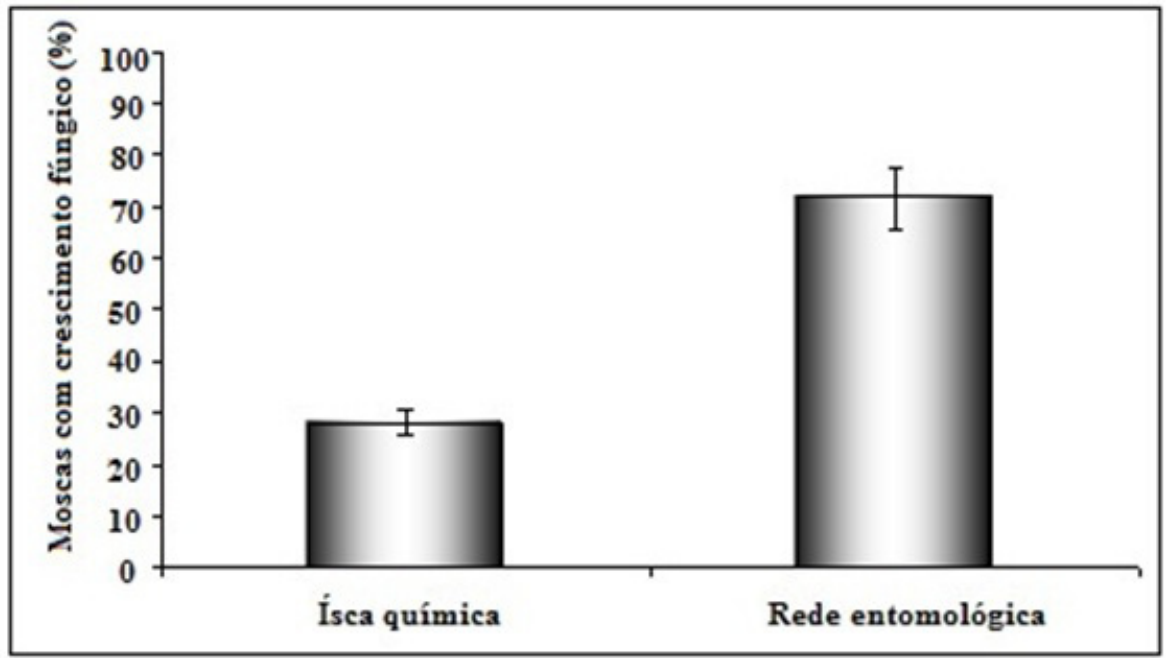

Fig. 1 - Avaliação do crescimento de fungos isolados de moscas domésticas (Musca domestica) capturadas através de dois sistemas: armadilhas contendo iscas químicas com inseticida imidacloprid eatravés de busca direta com rede entomológica.

\section{AGRADECIMENTOS}

À SOMAI NORDESTE S/A pelo apoio na pesquisa.

\section{REFERÊNCIAS}

ALVES, S.B. (Ed). Controle microbiano de insetos. 2.ed. São Paulo: Fealq, 1998. 1163p.

AXTELL, R.C. Poultry integrated pest management: status and future. Integrated Pest Management Reviews, v.4, p.53-73, 1999.

AXTELL, R.C.; ARENDS, J.J. Ecology and Management of arthropod pests of poultry. Annual Review of Entomology, v.35, p.101-126, 1990.

BANJO, A.D.; LAWAL, O.A.; ADEDUJI, O.O. Bacteria and fungi isolated from housefly (Musca domestica L.) larvae. African Journal of Biotechnology, v.4, n.8, p.708704, 2005.

BARNETT, H.L.; HUNTER, B.B. Illustrated genera of imperfect fungi. 4.ed. Minnesota: Burgués Publishing Company, 1998. 218p.

BICHO, C.L.; ALMEIDA, L.M.; RIBEIRO, P.B.; SILVEIRA JUNIOR, P. Flutuação de díptera em granja avícola, Pelotas, Rio Grande do Sul, Brasil. Iheringia, Série. Zoológica, v.94, n.2, p.205-210, 2004.

LOUREIRO, E.S.; MOINO JUNIOR, A.; ARNOSTI, A.; SOUZA, G. Efeito de produtos fitossanitários químicos utilizados em alface e crisântemo sobre fungos entomopatogênicos. Biological Control, v.31, n.2, p.263-269, 2002.

MOINO JUNIOR, A.; ALVES, S.B. Efeito de imidacloprid e fipronil sobre Beauveria bassiana (Bals.) Vuill. e
Metarhizium anisopliae (Metsch.) Sorok. e no comportamento de limpeza de Heterotermes tenuis (Hagen). Anais da Sociedade Entomológica do Brasil, v.27, n.4, p.611-619, 1998.

NUNES, M. Isolation of fungi in Musca domestica Linnaeus, 1758 (Diptera: Muscidae) captured at two natural breeding grounds in the municipality of Seropedica, Rio de Janeiro, Brazil. Memórias do Instituto Oswaldo Cruz, v.97, n.8, p.1107-1110, 2002.

QUICENO, J.; BASTIDAS, X.; ROJAS, D.; BAYONA, M. Moscas domésticas portadoras de patógenos. Revista U. D. C. A Actualidad E Divulgação Científica, v.13, n.2, p.23-29, 2010.

R DEVELOPMENT CORE TEAM. R: A language and environment for statistical computing. Vienna: Foundation for Statistical Computing, 2008.

ROMÁN, E.M.; TKACHUK, O.; ROMÁN, R. Detección de agentes bacterianos ver adultos de Musca domestica (Díptera: Muscidae ) recolectadas em Maracay, estado Aragua, Venezuela. Entomotropica, v.19, n.3, p.161-164, 2004.

SALES, M.S.N.; COSTA, G.L.; BITTENCOURT, V.R.E.P. Isolation of fungi in Musca domestica Linnaeus, 1758 (Diptera: Muscidae) captured at two natural breeding grounds in the municipality of Seropédica, Rio de Janeiro, Brazil. Memórias do Instituto Oswaldo Cruz, v.97, n. 8, 2002.

UGBOGU, O.C.; NWACHUKWU, N.C.; OGBUAGU, U.N. Isolation of Salmonella and Shigella species from house flies (Musca domestica L.) in Urutu, Nigeria. African Journal of Biotechnology, v.5, n.11, p.1090-1091, 2006.

Recebido em 30/3/12

Aceito em 19/4/13 